\title{
The Skill in Designing Explorative Learning Tools Of Mathematics Pre-Service Teachers Through Explorative Learning Based On Metacognitive Scaffolding
}

\author{
Hepsi Nindiasari $^{1, *}$, IndhiraAsih ViviYandari ${ }^{1}$, EtikaKhaerunnisa ${ }^{1}$, Aan SubhanPamungkas ${ }^{1}$ \\ ${ }^{1}$ Department of Mathematics Education, University of Sultan AgengTirtayasa, Serang, Indonesia.
}

\begin{abstract}
This study is back grounded by the fact that according to the result of TIMSS survey, Indonesian students' achievement in mathematics is still low. This study aims to see mathematics pre-service teachers' skill in developing learning tools after given explorative learning based on scaffolding metacognitive. The method of study use experimental quasi which is given to one group or class. The population of this study are mathematics pre-service teachers in University of Sultan AgengTirtayasa, Banten Province. The subject of sample taken is one class which is given initial treatment with explorative learning, then students performance in designing learning tools is assessed. Next, they are given explorative learning based on scaffolding metacognitive, and then their performance in designing learning tools is assessed. The instrument used is performance portfolio which is supported by a rubric to assess skill in designing explorative learning tools. The result shows that students in designing learning tools in the form of scenario based on Worksheet and in designing Worksheet after receiving explorative learning based on scaffolding metacognitive (very good category, mean score are 94.20 and 91.27) are better than before (explorative activity without scaffolding metacognitive) with very good category with the mean score are 85.27 and 86.11 ).
\end{abstract}

\section{INTRODUCTION}

Analysis and reasoning ability which is important ability and should be developed in mathematics learning in school still shows its low quality. In fact, students' lack in mathematical ability can be seen from the result of Trends in International Mathematics and Science Study (TIMSS) in 2015 which describe that in mathematics subject, Indonesian students are lack in all aspects of cognitive content. Indonesian students only master the routine problems, simple computation, and measure the knowledge of fact with daily context [1]. Indonesian students need reinforcement of ability in integrating information, drawing conclusion and generalizing the knowledge possessed to anotherthings. 
One thing which cause the lack of students' mathematical ability is learning activity in class. Mathematics learning activity in class still give less freedom for students to build their own knowledge. This is confirmed that learning process so far still dominated by teacher and did not give access to students to develop autonomously [2]. This cause the students' knowledge only limited to what had been taught by teacher so their ability to communicate the ideas in solving the problem do not developed optimally. Furthermore, stated that in learning process teacher did not organize students to discuss in heterogeneous group, so interaction and communication among students in learning are not implemented well [3].

Seeing the condition above. then the effort needs to be done to improve this condition. One of them is by developing pre-service teachers in study program they enrolled in lectures. This development direct pre-service teachers to be able to design meaningful learning for students, meaningful learning means that in learning activity, teacher give opportunity to students to investigate mathematical problem in the effort to build their own knowledge. One meaningful learning which can be developed is explorative learning.

Explorative learning offer opportunity to students to broaden their knowledge by using process and skill and connecting prior knowledge with their learning experience to solve the problem by involving students in problem solving process. Through exploration activity, students can find mathematical process in a such way so students experience themselves, able to create a hypothesis (conjecture), and then searching the answer for conjecture students make through observation activity.

In the effort to create explorative learning in class, of course pre-service teachers need to be trained in how to design active learning supported by learning tools among others are explorative Students Worksheet and learning scenario. In order that studentspossesability in designing explorative learning tools, of course they should be habituated by explorative learning activity in their lectures classroom. By experiencing directly explorative learning process, students are expected to be able to create explorative learning ideas for learning in their school in the future.

In the process of explorative learning implementation, students are confronted with a problem. With the problem given in the beginning of learning, students are expected to be able to utilize their knowledge and learning experience they posses before so they are able to generate creative ideas, identify the problem as initial process to solve the problem given. Explorative learning facilitate students to collect data and information to answer the problems posed through invention by investigating, searching relevant information, and making generalization from investigation result. After exploration process is implemented, students are directed to apply the concept which had been obtained by confronting the task to make explorative learning tools.

In exploration process implemented by students, the role of lecturer as facilitator in giving scaffolding to students who find difficulty. Because in initial stage, students need support from more competent person to be able to reach ZPD (zone of proximal development). This scaffolding is intended as help or guidance from lecturer in the initial of learning then giving opportunity to students to take over more responsibility after they can do it by themselves. Lecturer help is very needed to make them become more directed so the process of learning implementation and the achieved goal can be implemented well. This scaffolding is needed because actually students have rich potency but they had not possessed ability to organize information or initial ability. The ability to organize according to [4] is known as one form of metacognition ability.

Metacognition is a part in learning, so metacognition needs to be strived for in the implementation of learning process in class [5]. Someone do metacognitive in two ways: 
firstly, individual should aware of their own cognitive process (for example self-monitoring or self-regulation); secondly, individual should be able to apply cognitive process possessed for learning goal or design the solution for problem (for example, using critical thinking or reflective assessment) [6].

The importance of metacognitive in learning not only for mathematics pre-service teachers, but also for students. Metacognitive can motivate performance enhancement and efficiency of problem solving through reflection activation done by students [7]. This is corroborated also by Garciawho said that metacognition in learning can make students to more realize their performance quality, even when mathematical problem is given to students, they can realize how importance to solve that problem not merely for accomplishing it, but also for the quality of task accomplishment [8]. The result study of Yildirim showed that there is positive correlation which is significant between the level of students' metacognitive awareness and the level of their problem solving related to routine and non routineproblem [9]. To involve one's metacognition when he or she is in their $\mathrm{ZPD}$, then it needs help in the form of scaffolding from lecturer or more able person. The help intended here not by giving idea directly related to the task of designing learning tools, but the help in directing students to involve their metacognition in learning. The help in this case are question, direction or command, in which the questions direct to metacognitive skill which is termed by scaffolding metacognitive. The question or help related to idea, knowledge which had been possessed which is related to the present knowledge, planning in developing learning tools, and reflection and evaluate the tools which had been implemented. The question words which had been used are what? why? how?

Seeing explorative learning process based on scaffolding metacognitive is tightly related to investigation activity containing challenging learning tasks and students take bigger role in their learning responsibility. Therefore, it is supposed that explorative learning based on scaffolding metacognitive can contribute well for mathematics preservice teachers' skill in designing explorative learning tools. So, the problem formulation in this study is how does the skill mathematics pre-service teachersl in designing explorative learning tools through explorative learning based on scaffolding metacognitive?

\section{RESEARCH METHOD OF STUDY}

The aim of this study is to see the skill in designing explorative learning in students before and after they are given explorative learning based on scaffolding metacognitive. So the design of this study use experimental quasi with modified pretest-posttest design.
$\mathbf{k}$
$\mathbf{X}_{1}$
$\mathbf{O}_{1}$
$\mathbf{X}_{2}$
$\mathbf{O}_{2}$

Experiment Explorative Performance

The population of this study are mathematics pre-service teachers in University of Sultan AgengTirtayasa. The subject of study sample is one class of mathematics pre-service teachers in University of Sultan Agent Tirtayasa with total of 28 students. In this study, the subject is given explorative learning first, then performance test in designing learning is given. It is followed by explorative learning with scaffolding metacognitive, and in the final experiment, performance test is given anymore.

The instrument used in this study is portfolio of skill in designing explorative learning. The rubric of assessment use analytic Rubric approach. Analytic rubric is a rubric of skill in designing learning scenario comprising assessment of performance in developing explorative worksheet and worksheet (WS) based learning scenario. The assessment rubric of explorative worksheet performance comprise the element of information and question 
asking with grading score of 4, 3, 2, 1 grading, whereas the assessment of WS based scenario learning comprise the elements of introductory activity, core activity, and closing by using grading score of 3.2. 1. Next. score from this rubric is described and analyzed by using difference test to see whether or not there is difference in students' skill in designing learning before and after treatment given.

Data is analyzed by quantitative and qualitative approach. Data processing use wilcoxon test with related sample. This test aims to see the difference of ability before and after explorative learning based on scaffolding metacognitive is given in the same group.

\section{RESULT AND DISCUSSION}

The data to see mathematics pre-service teachers' skill is taken from portfolio of learning tools made by students and assessed by using rubric of learning tools performance both in worksheet and learning scenario. Table 1 shows the result of mean score for students' skill in developing learning tools.

Table 1.Mean Score of Students' Skill in Developing Learning Tools

\begin{tabular}{|c|c|c|c|c|}
\hline & \multicolumn{2}{|c|}{ Worksheet (WS) } & \multicolumn{2}{c|}{ WS based scenario } \\
\hline \multirow{2}{*}{ Mean } & $\begin{array}{c}\text { Explorative } \\
\text { (EP) }\end{array}$ & $\begin{array}{c}\text { Explorative Scaffolding } \\
\text { Metacognitive (ESM) }\end{array}$ & $\begin{array}{c}\text { Explorative } \\
\text { (EP) }\end{array}$ & $\begin{array}{c}\text { ExplorativeScaffolding } \\
\text { Metacognitive (ESM) }\end{array}$ \\
\cline { 2 - 5 } & 85,27 & 94,20 & 86,11 & 91,27 \\
\hline
\end{tabular}

From the table 1, mean gain of skill in developing WS based learning tools and learning scenario in EP and ESM learning in very good category. These two learning enable mathematics pre-service teachers to develop learning tools. This is supported by difference test that WS development with ESM learning is better than EP learning. This reality is shown by p-value (sig) 0.004 which is less than $\alpha=0.05$ so $\mathrm{H}_{0}$ is rejected and $\mathrm{H}_{\mathrm{a}}$ is accepted.

Similarly with skill in designing WS based learning scenario. $\mathrm{H}_{0}$ is rejected and $\mathrm{Ha}$ is accepted, because p-value (Sig) of 0,004 which is less than $\alpha=0,05$ It shows that skill in designing learning scenario with explorative learning based on scaffolding metacognitive is better than explorative learning.

The result of calculation which is related to difference test can be seen in the following table:

Table 2. Recapitulation Result of Difference Test for Skill in Designing Learning Tools

\begin{tabular}{|c|c|c|}
\hline Learning & Worksheet & WS Based Scenario \\
\hline Explorative (EP) & P-Value $=0,004$ & P-Value $=0,004$ with \\
& with $\alpha=0,05$ & $\alpha=0,05$ \\
Explorative Scaffolding & Ho is rejected & Ho is rejected \\
Metacognitive (ESM) & & \\
\hline
\end{tabular}

Based on that result that explorative learning based on scaffolding metacognitive enable mathematics pre-service teachers toposses skill in designing learning tools, then the lecturers are advised to apply that skill. Because this learning not only demand students to conduct investigation, analysis, and discussion activity during learning to train skill in designing learning tools but also lecturer help students to aware of their metacognitive ability by scaffolding metacognitive. The lecturer help students to find idea, to relate the old knowledge to new knowledge, to design learning tools, and to evaluate learning tools which had been designed and implemented. The question asked related to scaffolding metacognitive, for example: what idea will be raised by you in making WS and learning scenario? What media which is appropriate in supporting WS in order that students understand the concept given? How do you feel when implementing scenario and WS based 
learning? Etc. It is hoped that these questions can make students aware to control their thinking activity so later they are able to reflect on themselves. Explorative learning based on metacognitive is held in group settingso it can facilitate students to interact with their peers and if they find difficulty the can discuss with the others. Lin stated that the creation of supportive social environment can support students' metacognitive development so it can motivate them to do active activity in learning [10]. The study result of Molenaar et al showed that scaffolding influence positively social metacognitive interaction within group and found significant relation between students' participation in social metacognitive interaction within group and students' metacognitive knowledge [11].

The ability to design learning tools given by group setting with good result is one task which is collected and assessed by an assessment rubric.It is included in authentic task criteria. The authentic task which is related to metacognitive instruction in this case scaffolding metacognitive had showed a better result without using metacognitive instruction. This is in accord with (ramarski et al, that students who are taught by learning with cooperative and metacognitive setting have authentic task which is better compared with students without metacognitive instruction [12]. In addition, there is enhancement in this result of study if compared with study of (Nindiasari\&Pamungkas) when analyzed students' ability in developing Explorative Worksheet and learning scenario [13]. The study conducted by Nindiasari and Pamungkas in 2016 with students group learning only capable to design learning tools with good category, but in this study both with explorative learning and explorative with scaffolding metacognitive are in very good category.

If it is analyzed, the result of WS design made by students in explorative learning based on scaffolding metacognitive for the element of information is that $82.14 \%$ students have been able to arrange the information with not too much and too little, and support problem solving. Similarly with the element of questioning in which $82.14 \%$ students have made higher order question which encourage students to conduct investigation and encourage them to discuss. Compared with explorative learning activity without scaffolding metacognitive in WS development for the element of information which is not too little which encourage students to conduct investigation and encourage them to discuss are only $67 \%$ and $53.56 \%$ respectively. This data shows that there is enhancement from explorative learning activity (EP) to explorative activity with scaffolding metacognitive (ESM). Its enhancement for the element of information is $15.4 \%$ and the element of questioningis $28.57 \%$. In fact, the highest enhancement is in questioning. Before explorative scaffolding metacognitive is given, some students only make question which is usual exercise, but after explorative scaffolding metacognitive is given, students are encouraged to reflect and control their thinking activity through questioning encouraged by lecturer so they are aware of what should be done to improve WK they make.

The result of enhancement for skill in designing WK is followed by enhancement in designing learning scenario comprising the elements of introductory activity, core activity and closing activity. Students who design learning scenario after obtaining explorative learning with scaffolding metacognitive for the element of design introductory activity is $100 \%$ had designed introductory activity which remind students to prerequisite related to the material which will be delivered (doing apperception), whereas in the element of core activity, 71.4\% students had designed activity which reflect WK they make, demand students to do active and explorative learning, and in the element of closing activity, $50 \%$ students had done reflection, make conclusion and give task and motivate students to learn. If compared with explorative learning without scaffolding metacognitive, the element of introductory activity is $89.29 \%$, the element of core activity is $60.7 \%$ and the element of closing activity is $32.14 \%$ respectively. The highest enhancement in designing closing activity is $17.86 \%$ compared with another element which only $10.71 \%$. In fact, scaffolding 
metacognitive which habituate students to control their thinking process through questions given by lecturer can habituate students to do reflection activity and drawing conclusion in their learning scenario. The element of closing activity both in EP and ESM learning needs more attention. Students need to be trained in designing good closing activity particularly reflection activity.

\section{CONCLUSION}

Students with explorative learning based on scaffolding metacogniveare better in their ability in developing learning tools compare to when they only do explorative activity. Lecturers need to implement explorative activity based on scaffolding metacognitive when designing learning tools.

\section{References}

1. Kemdikbud. Diagnosis of TIMSS Result 2015 For Quality and Achievement Enhancement. (2015).

2. Trianto. Designing Productive Innovative Learning. Jakarta: Kencana. (2010).

3. A. Murni., Y. T. Nurul, and T. Solfitri. The Application of Active Learning Method with Group to Group Exchange (GGE) Type to Enhance Mathematics Learning Outcome of Students X Social Studies MAN 2 Model Pekanbaru, JOER , 11, No. 2, P. 2. (2010).

4. Awi. The tracing of Scaffolding Metacognitive Types Needed by Students of lass XI Natural Science Senior High School in Solving Mathematical Problem, The National Seminar Prosiding Seminar of Mathematics and Mathematics,(2010).

5. G. Schraw, K.J. Crippen \& K. Hartley. Promoting Self-Regulation in Science Education: Metacognition as Part of a Broader Perspective on Learning. JRSE, 36, pp 111-139 . (2006).

6. Hogan, et all. Metacognitive Skill Development and Applied Systems Science: A Framework of Metacognitive Skills, Self-regulatory Functions and Real-World Applications. JML, (2014).

7. B. Hoffman and A. Spatariu. The influence of self-efficacy and metacognitive prompting on math problem-solving efficiency. JCEP, 33, Issue 4, October 2008, Pages 875-893. (2008).

8. T. García, C. Rodríguez, P. González-Castro, et al. Elementary students' metacognitive processes and post-performance calibration on mathematical problem-solving tasks. JML, 11, pp 139-170. (2016).

9. S. Yıldırım \& Ersözlü. The Relationship Between Students' Metacognitive Awareness and their Solutions to Similar Types of Mathematical Problems. EJOMSATE, 9 (2013).

10. X. Lin, ETR\&D. Designing metacognitive activities. JETRAD, 49, pp 23-40. (2001).

11. I. Molenaar, et all . The effects of scaffolding metacognitive activities in small groups. JciHB, 26, Issue 6. (2010).

12. M. Kramarski, et all. The Effects of Metacognitive Instruction on Solving Mathematical Authentic. JML. 49, No. 2 , pp. 225-250 .(2002)

13. H. Nindiasari, \& A.Pamungkas, Analysis of Mathematics Pre-Service Teachers' Ability in Developing Explorative Worksheet along with Learning Scenario 365368. (2016). 